\title{
ARSITEKTUR LANSEKAP SEBAGAI KONSEP FASILITAS OLAH RAGA HIJAU KEMAYORAN
}

\author{
Vincent Damayanto ${ }^{1)}$, Denny Husin ${ }^{2)}$ \\ 1)Program Studi S1 Arsitektur, Fakultas Teknik, Universitas Tarumanagara, damayantov@gmail.com \\ 2)Program Studi S1 Arsitektur, Fakultas Teknik, Universitas Tarumanagara, denny@ft.untar.ac.id
}

\begin{abstract}
Abstrak
Fenomena penduduk yang tinggal disekitar kawasan Kemayoran merupakan masyarakat modern dengan berbagai rutinitas dan aktivitas serta mobilitas yang tinggi. Kebiasaan aktivitas ini mengubah psikologi mereka terutama masyarakat yang tinggal di area yang padat. Kemayoran merupakan kawasan yang didominasi oleh hunian baik hunian vertikal maupun hunian horizontal. Hal ini berdampak terhadap tingkah perilaku masyarakat yang tinggal di sekitar kawasan ini. Isu pada kawasan ini adalah penduduk kawasan dipenuhi olah masyarakat yang aktif bekerja dan mempunyai kebiasaan untuk hidup menyendiri dan tidak bersosialisasi. Masalah yang terjadi pada kawasan ini adalahnya fungsi tempat komunal yang sudah disiapkan tidak dapat memenuhi kebutuhan penghuni serta tidak adanya ruang terbuka sebagai titik temu antara penghuni hunian vertikal dengan penghuni hunian horizontal. Sebagai sebuah respon terhadap isu yang terjadi pada kawasan ini maka tujuan dari pembentukan proyek ini adalah menjadi sebuah attractor kawasan yang dapat mengubah perilaku masyarakat sekitar. Langkah yang digunakan yaitu membuat sebuah karya dan program arsitektur sebagai pengubah psikologi manusia dimana pemilihan bahan bangunan, bentuk serta sirkulasi bangunan dibentuk agar dapat mempengaruhi psikologi pengguna. Serta menggabungkan unsur arsitektur dengan alam dapat menyembunyikan keberadaan bangunan dari lingkungan yang sudah sangat padat.
\end{abstract}

Kata kunci: kepadatan; lansekap; psikologi

\begin{abstract}
The phenomenon of people living in the Kemayoran area is a modern society with various routines and activities as well as high mobility. The habit of this activity changes their psychology, especially people who live in dense areas. Kemayoran is a dense area of housing both vertical housing and horizontal housing, this has an impact on the behavior of people who live around this area. The issue in this area is that the inhabitants of the area are filled with people who are actively working and have the habit of living alone and not socializing. The problem that occurs in this area is the function of the communal place that has been prepared can not meet the needs of residents and the absence of open space as a meeting point between residents of vertical homes with horizontal residents. As a response to issues that occur in this region, the purpose of forming this project is to become an area attractor that can change the behavior of the surrounding community. The step used is to create an architecture as a modifier of human psychology where the selection of building materials, shapes, and circulation of buildings is formed so that it can influence the user's psychology. As well as combining elements of architecture with nature to hide the existence of buildings from a very crowded environment.
\end{abstract}

Keywords: density; landscape; psychology 


\section{PENDAHULUAN}

Jumlah penduduk yang terus meningkat merupakan salah satu permasalahan bagi kota. Dengan terus bertambahnya permintaan hunian namun dihadapkan dengan kendala keterbatasan lahan membuat masyarakat dengan pendapatan menengah bawah kesulitan untuk mendapatkan hunian. Untuk menjawab permasalahan ini maka hal yang dilakukan ialah menambah jumlah hunian vertikal. Hal ini tentu berdampak tingkat perilaku penghuni didalamnya, dimana masyarakat kota yang tinggal di area padat memiliki tingkat stress yang lebih tinggi (Evans, 1984). Kualitas hidup masyarakat serta kebiasaan sangat terpengaruhi oleh banyak hal seperti kepadatan pendudukan dan juga ketersediaan fasilitas-fasilitas penunjang kawasan. Pada daerah yang memiliki kepadatan yang tinggi akan lebih susah untuk meningkatan kualitas penduduk. Hal ini akan memicu hal-hal seperti permasalahan ekonomi, kesejahteraan serta keamanan kawasan (Christina, 2015).

Kemayoran merupakan kawasan yang strategis, baik untuk kepentingan perekonomian yang dimana menjadi pusat perkembangan perdagangan dan jasa di kota Jakarta. Hal ini membuat tingkat pembangunan kawasan Kemayoran cukup pesat dibanding kawasan lain. Kawasan kemayoran juga dipenuhi dengan bangunan vertikal baik hunian maupun perkantoran seperti rumah susun dan juga apartemen (Bungas, 2017). Kesibukan dalam pekerjaan membuat orang tidak memiliki waktu untuk mempersiapkan kebutuhan hariannya. Maka dari itu banyak masyarakat yang terutama masih aktif bekerja dan baru berumah tangga banyak yang tinggal di apartemen yang lebih mudah memberikan kebutuhan hariannya (Ruchimat, 2007). Hal ini membentuk perilaku masyarakat kemayoran yang kebanyakan adalah masyarakat yang masih aktif bekerja.

Dari hasil observasi ke lapangan didapatkan bahwa masyarakat yang tinggal di hunian vertikal disekitar kawasan Kemayoran merupakan masyarakat yang dalam usia aktif berkerja. Cara pandang masyarakat modern ini cenderung hanya berorientasi pada diri sendiri dan hal ini membuat mereka untuk lebih memilih cara hidup yang individualisme (Harvina, 2016). Tingkat segregasi pada kawasan ini juga sangat terasa sebab tingkat perekonomian pada kawasan yang sangat dynamic pada lingkup yang kecil membuat kawasan ini merasa terbagi meskipun hanya terpisah oleh sebuah ruas jalan. Hal ini membuat kesenjangan sosial pada kawasan ini sangat terlihat, terlebih lagi tidak adanya ruang terbuka yang dapat digunakan untuk melakukan kegiatan bersama dengan tujuan menyatukan kawasan ini (Dr. Adon Nasrullah Jamaludin, 2017).

\section{Rumusan Permasalahan}

Upaya pihak developer apartemen dalam menyelesaikan minimnya interaksi sesama penghuni apartemen adalah dengan menyediakan tempat berkumpul dan interaksi seperti lobby dan lounge. Namun dalam praktiknya hal ini tidak membantu menghubungkan sesama penghuni apartemen dan membuat ruang ini menjadi tidak berfungsi. Agar masyarakat dapat menikmati sebuah tempat interaksi maka eksistensi antara ruang terbuka dengan bangunan sekitar harus diimbangi (Hari H. Siregar, 2015). Terlebih lagi tidak adanya magnet kawasan yang memiliki kondisi yang menyenangkan untuk sebagai tempat berkumpul dan tempat pertemuan bagi masyarakat yang tinggal di hunian vertikal dengan masyarakat yang tinggal di perumahan horizontal sekitar kawasan (Dr. Adon Nasrullah Jamaludin, 2017).

\section{Tujuan}

Tujuan utama pada proyek ini adalah mengubah kebiasaan masyarakat sekitar yang berada di sekitar kawasan penelitian agar dapat lebih bersosialisasi dengan sesama, dengan membuat ruang terbuka di tengah kepadatan kota diharapkan dapat meningkatkan kualitas hidup masyarakat sekitar. Serta proyek ini juga diharapkan untuk dapat menjadi ruang terbuka yang 
memiliki kondisi yang nyaman dan menyenangkan agar dapat menjadi titik pertemuan antara penghuni rumah vertikal dengan penghuni perumahan horizontal agar dapat mengurangi tingkat segregasi kawasan yang sangat terasa saat ini. Dan juga sebagai tempat pemberhentian bagi masyarakat yang ingin pergi sejenak dari kehidupan kota yang sangat padat dan melelahkan sehingga dapat mengurangi tingkat stres kawasan.

\section{KAJIAN LITERATUR}

\section{Third Place}

First place adalah sebuah rumah tinggal bagi seseorang sedangkan Second place adalah tempat kerja seseorang dimana dia menghabiskan kebanyakan waktunya. Kemudian muncul sebuah third place sebagai "jangkar" kehidupan masyarakat yang memfasilitasi dan membina untuk terjadinya interaksi antar masyarakat. Dengan kata lain third place adalah tempat dimana seseorang bisa bersantai di tempat publik (Oldenburd, 1989). Skala sebuah third place itu sendiripun juga berbeda-beda bergantung dengan tempat serta kebiasaan masyarakat sekitar, beberapa negara di Eropa melakukan pertemuan di tempat-tempat berskala besar seperti plaza, theather dan juga mall beberda dengan masyarakat di Amerika yang cenderung bertemu di tempat-tempat dengan skala yang lebih kecil seperti café (Jaya, 2018).

\section{Arsitektur dan Psikologi}

Psikologi secara langsung berhubungan dengan budaya, seni, dan arsitektur. Penggunaan yang tepat dari berbagai artistik komponen seperti warna, ruang dan ukuran memiliki kapasitas untuk mencerahkan atmosfer lingkunan, Sebegai contoh, sebuah ruangan dengan dinding yang berwarna putih membuat pengguna merasa ringan serta membuat ruang lebih cerah dan lebih menyenangkan berada didalamnya (Janetius, 2016). Hal ini adalah interaksi antara manusia dengan lingkungan. Desain dari lingkungan sekitar kita termasuk dengan landscape dan bangunan memiliki pengaruh terhadap kondisi psikologi serta kebiasaan kita. Kualitas lingkungan alam juga membantu meningkatkan suasana hati, perhatian, dan juga fungsi kognitif (Coburn, 2019).

\section{Olah Raga Terhadap Sosialisasi}

Hasil studi menunjukan bahwa dalam sebuah grup, orang akan lebih mudah bersosialisasi ketika melakukan kegiatan olah raga bersama. Hal ini bertujuan agar para penghuni kawasan penlitian yang cenderung tidak berinteraksi antara satu dengan yang lain dan lebih ingin berkelompok sesuai dengan ketertarikan masing-masing kelompok dapat lebih bersosialisasi dan mengenal orang disekitarnya sehingga area tengah dapat penuhi orang-orang yang saling mengenal dan tidak saling berkelompok (Davis, 2015). Olah raga itu sendiri juga memiliki banyak manfaat tidak hanya untuk meningkatkan kesehatan tetapi olah raga juga terdapat banyak fungsi lain meningkatkan tingkat kepercayaan diri dan juga tingkat kebahagian serta mengurangi tingkat stress (Collins, 2020).

\section{Food and Mood}

Makanan yang kita makan dalam keseharian tentu tidak hilang begitu saja, apa yang kita makan sangat berpengaruh terhadap suasana hati kita. Beberapa zat buatan seperti penguat rasa dapat membuat mood yang kurang baik (Uma Naidoo, 2018). Maka dari itu pemilihan bahan makanan serta menjauhi makan siap saji dapat membantu mood kita sehari-hari dimana hasil penelitian juga didapatkan bahwa penambahan konsumsi sayur-sayuran, bijibijian dan makanan yang banyak mengandung omega-3 juga dapat membantu tingkat mood kita (Opie, 2017). Selain itu banyak hal lain yang dapat meningkatkan tingkat suasana hati kita salah satu unsur yang berperan ialah reaksi kimia dalam tubuh kita yang menghasilkan hormon endorfin yang berguna sebagai penghilang stress dan penenang diri (Muhlisin, 2019). 


\section{METODE}

\section{Metode Perancangan}

Metode perancangan yang digunakan pada proyek ini adalah psikologi arsitektural, bahan, tekstur, detail, warna pada materi untuk mempengaruhi psikologi manusia. Keberadaan taman kota sendiri dapat membantu memenuhi kebutuhan mental manusia. Maka dari itu pemilihan bahan seperti bahan bebatuan dan dinding kayu serta bentuk bangunan dibuat sedemikian rupa dengan tujuan mengurangi keberadaan bangunan (Andrahan, 2012). Masyarakat perkotaan juga memiliki tuntutan hidup yang lebih tinggi dibanding masyarakat pedesaan, kehidupan kota seperti itu secara relatif akan menimbulkan reaksi stress (Kusmaryani, 2015). Maka pembentukan sirkulasi dan juga perasaan dalam sebuah bangunan harus dipertimbangkan agar dapat mengurangi tingkat stres pengguna bangunan. Penggunaan ramp dan perbedaan peil tanah juga berguna untuk meransang hormon erdorphin yang berperan dalam mengurasi rasa stress sehingga masyarakat sekitar dapat lebih mudah bersosialisasi.

\section{DISKUSI DAN HASIL}

\section{Data Tapak}

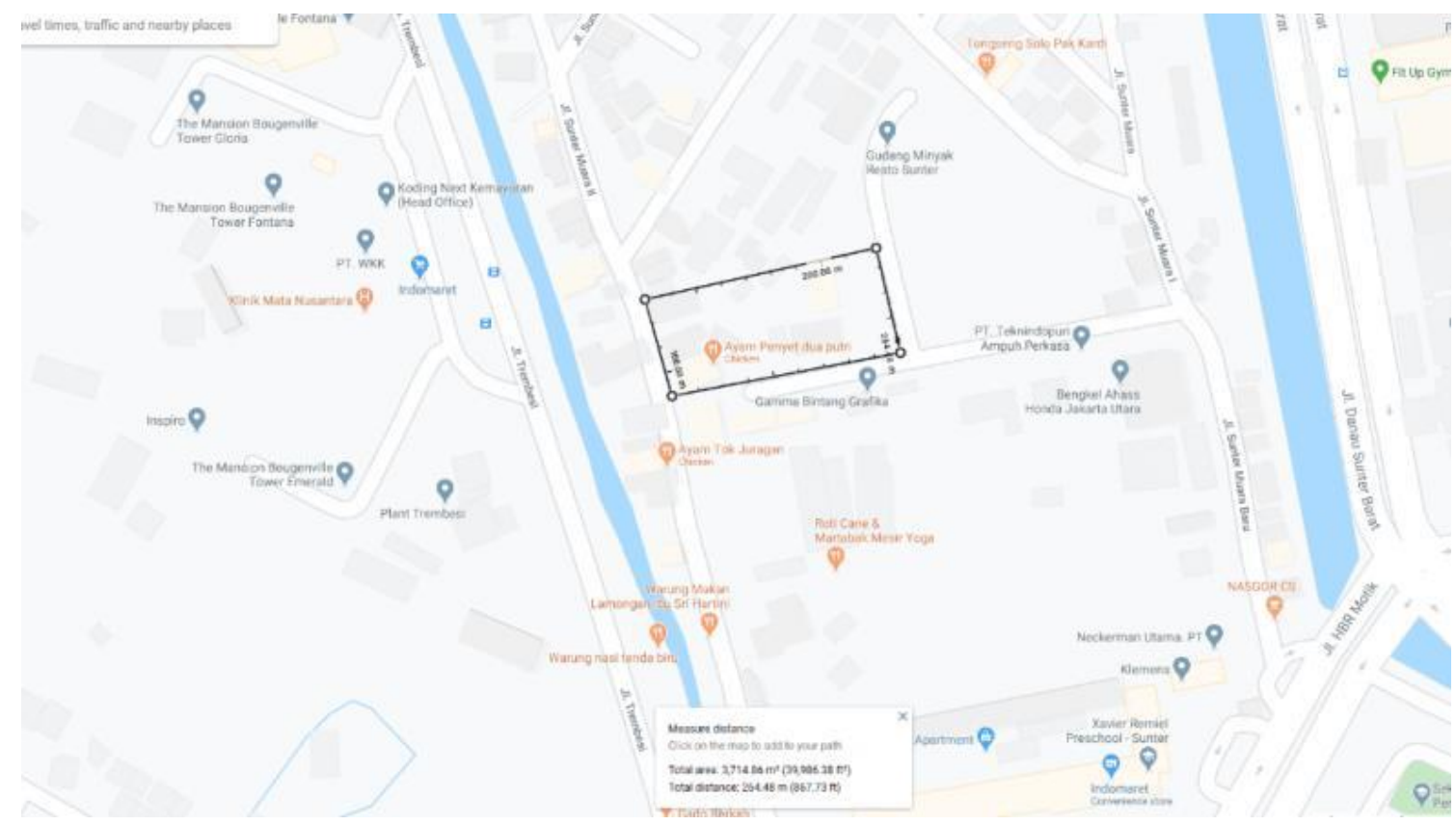

Gambar 2. Lokasi dan Bentuk Tapak

Sumber : https://www.google.com/maps/@-6.1481097,106.8560387,18z, diunduh 3 Juni 2020

Informasi Tapak:

a. Tapak terletak di Kelurahan Sunter Agung, Kecamatan Tanjung Priok, di Jl.Sunter Muara II dan JI. Sunter Muara Baru sebagai akses masuk untuk ke dalam area tapak.Tapak saat ini merupakan sebuah area perumahan kumuh, menurut survey dan peta penggunaan lahan. Di sekitarnya merupakan area perumahan dan kawasan niaga.

b. Peruntukan lahan menurut RUTR terkategori sebagai zona kuning atau zona perumahan dengan KDB Sedang - Tinggi. Meskipun zona tergolong sebagai zona perumahan, sesuai dengan RUTR, zona kuning juga diizinkan sebagai Taman Rekreasi, Tempat Bermain Lingkungan, Lapangan Olahraga, dll. Tapak ini memiliki jarak sekitar $200 \mathrm{~m}$ dari jalan utama, sehingga tidak jauh untuk berjalan kaki ke daerah tapak dari jalan utama dan kawasan niaga di sekitarnya.

c. Tapak ini memiliki batasan zonasi sebagai berikut : KDB : 50, KLB :2, KDH : 35, KB : 4, Luas Lahan: $\pm 3.700 \mathrm{~m} 2$. 


\section{Program Kegiatan}

Fasilitas Olah Raga Hijau Kemayoran (Kemayoran Sport Park) merupakan sebuah proyek yang pada mulanya dibuat untuk menyatukan masyarakat Kemayoran yang kekurangan area hijau dikawasan yang padat untuk melepaskan stress. Jenis program yang digunakan terbentuk berdasarkan permasalahan yang ada di kawasan yaitu penyimpangan perilaku masyarakat yang tinggal di dalamnya. Maka dari itu program yang dipilih adalah program yang dapat membantu mengurangi segregasi kawasan serta juga program yang dapat memancing pengubahan psikologi masyarakat yang tinggal didalamnya. Program ini sendiri juga harus dapat menjadi attractor bangunan yang memiliki kondisi yang menyenangkan agar dapat menjadi titik pertemuan masyarakat. Adapun program utama dari proyek adalah: area olah raga, area makan, area jogging dan taman.

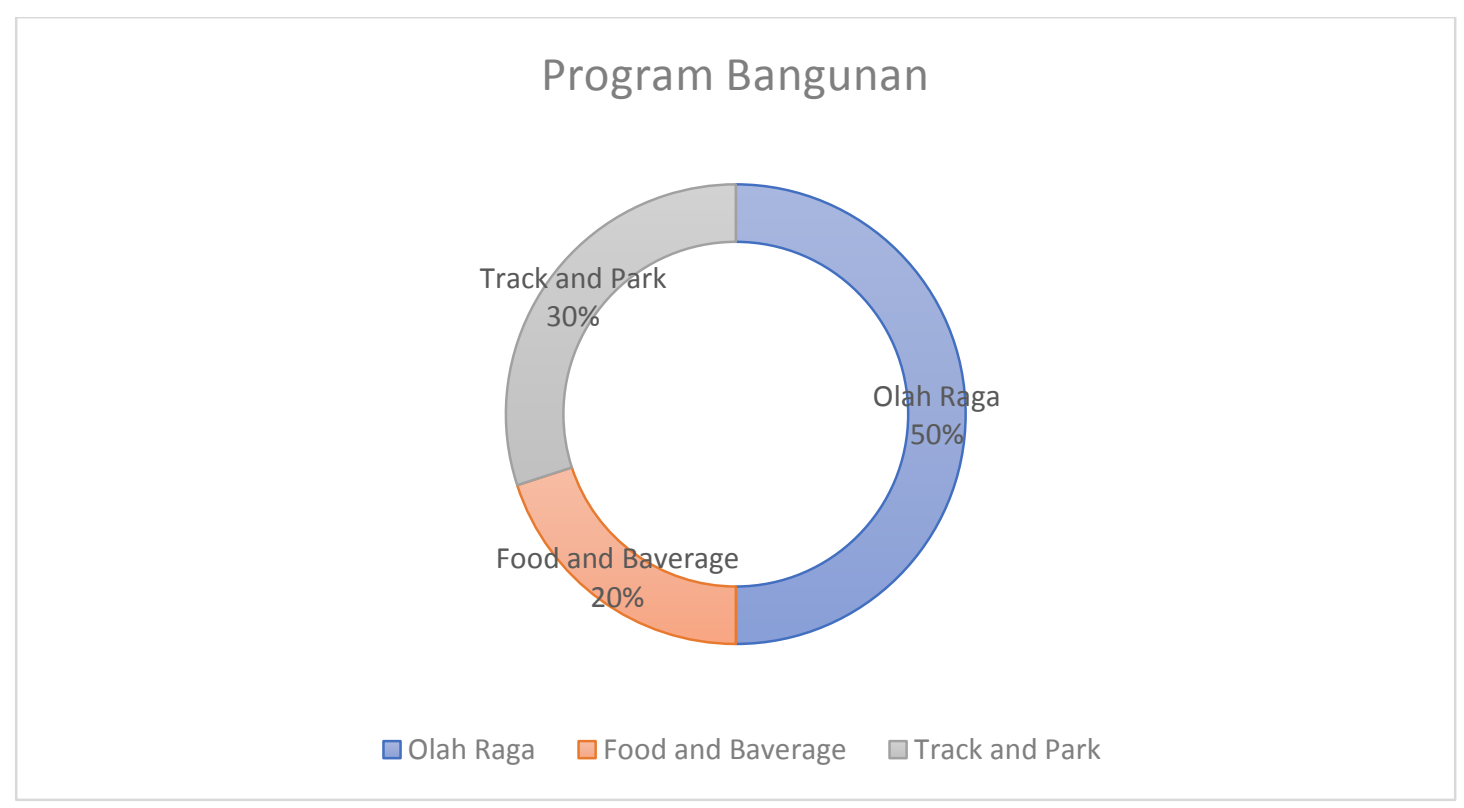

Gambar 3. Presentasi Program Bangunan

Sumber : Penulis, 2020

\section{Area Olah Raga}

Sebuah area olah raga merupakan upaya utama dalam mempersatukan masyarakat yang tinggal di sekitar kawasan. Salah satu kegunaan olah raga dapat membantu meningkatkan tingkat kepercayaan diri serta kemampuan social yang sangat dibutuhkan kawasan ini. Area olah raga sendiri terbagi menjadi beberapa bagian, gym area sebagai salah satu program utama dengan upaya mengikat masyarakat dengan cara berolah raga bersama. Terlebih lagi olah raga seperti gym memiliki fleksibilitas yang cukup tinggi cocok dengan masyarakat yang mempunyai rutinitas yang tinggi. Kemudian sand board area sebagai salah satu program utama lainnya bertujuan sebagai attractor kawasan yang unik dan olah raga yang belum dijumpai sebelumnya, membawa sebuah olah raga yang biasanya tidak dijumpai di area perkotaan diharapkan dapat mengundang masyarakat (lih. Gambar 4).

\section{Area Makan}

Area makan pada kawasan ini sebagai program pendukung terutama jenis makanan yang dijual pada area ini juga memikirkan dampaknya pada konsumen. Apa yang kita makan sangat berdampak terhadap mood kita dimana beberapa jenis makanan yang banyak mengandung zat buatan seperti penguat rasa dapat membuat mood yang kurang baik .Dari hasil penelitian maka ditentukan bahwa jenis makanan yang akan dijual pada kawasan ini berupa buahbuahan, sayuran, biji-bijian serta tidak menjual makanan yang mengandung lemak lebih jenuh 
dan perbanyak makanan yang mengandung omega-3. Hal ini sangat membantu dalam meningkatkan mood konsumen yang nantinya juga akan sangat berpengaruh kepada interaksi sesama didalam bangunan (lih. Gambar 6).

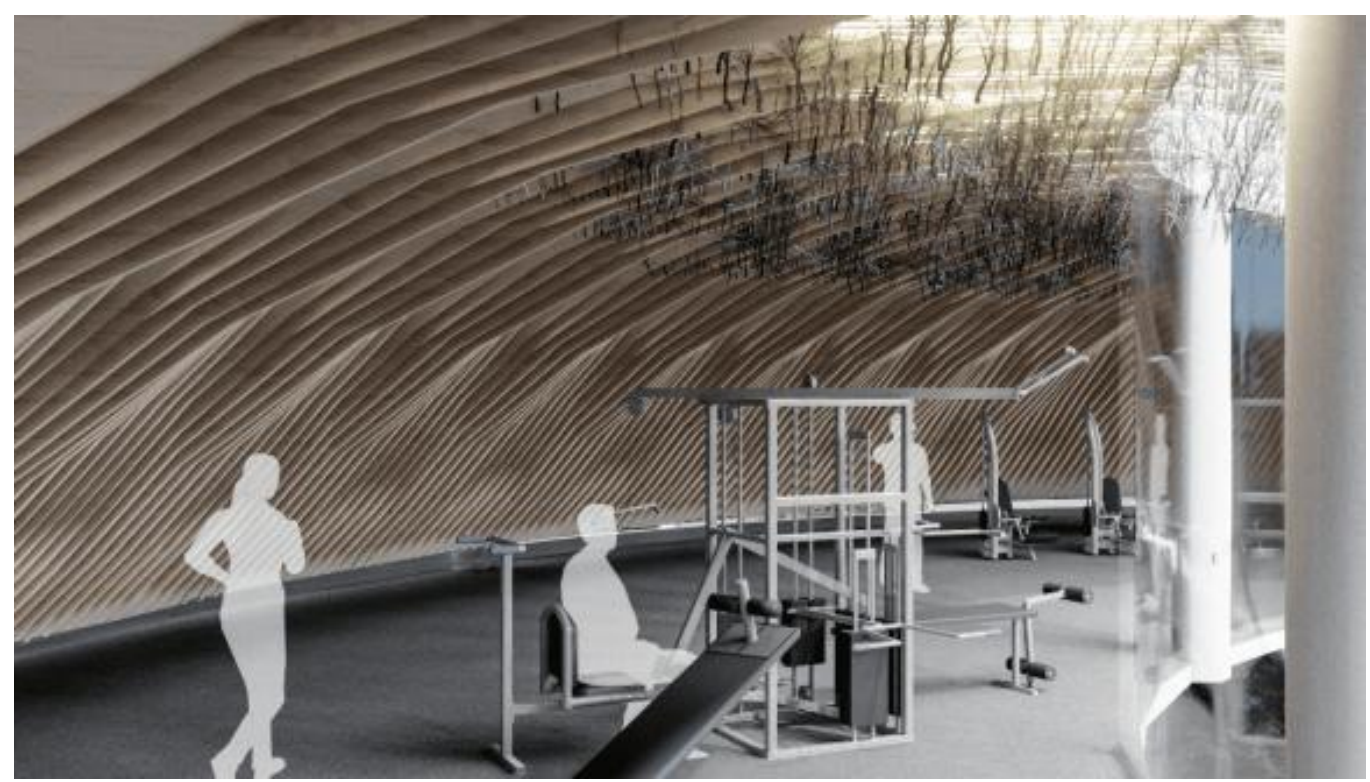

Gambar 4. Visualisasi Area Gym Sumber: Penulis, 2020

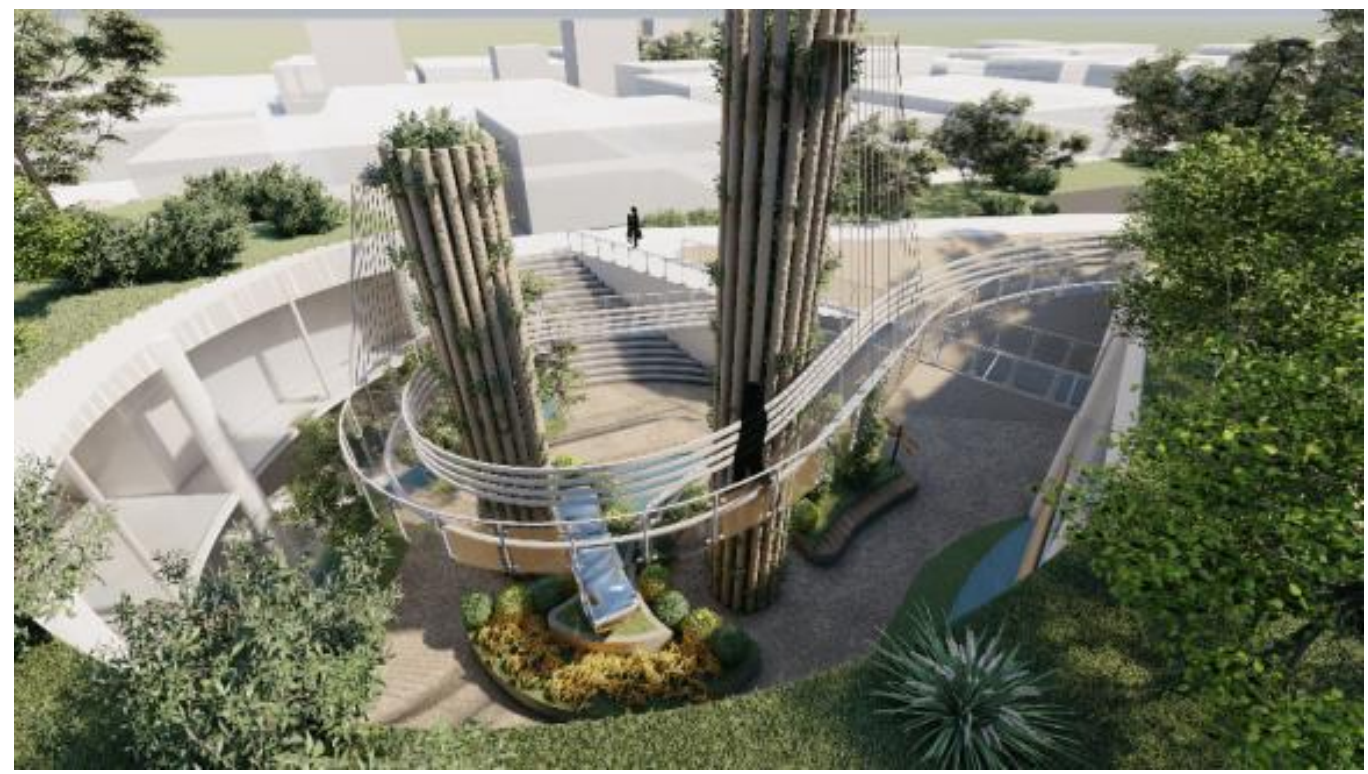

Gambar 5. Visualisasi Area Future Park Sumber : Penulis, 2020 


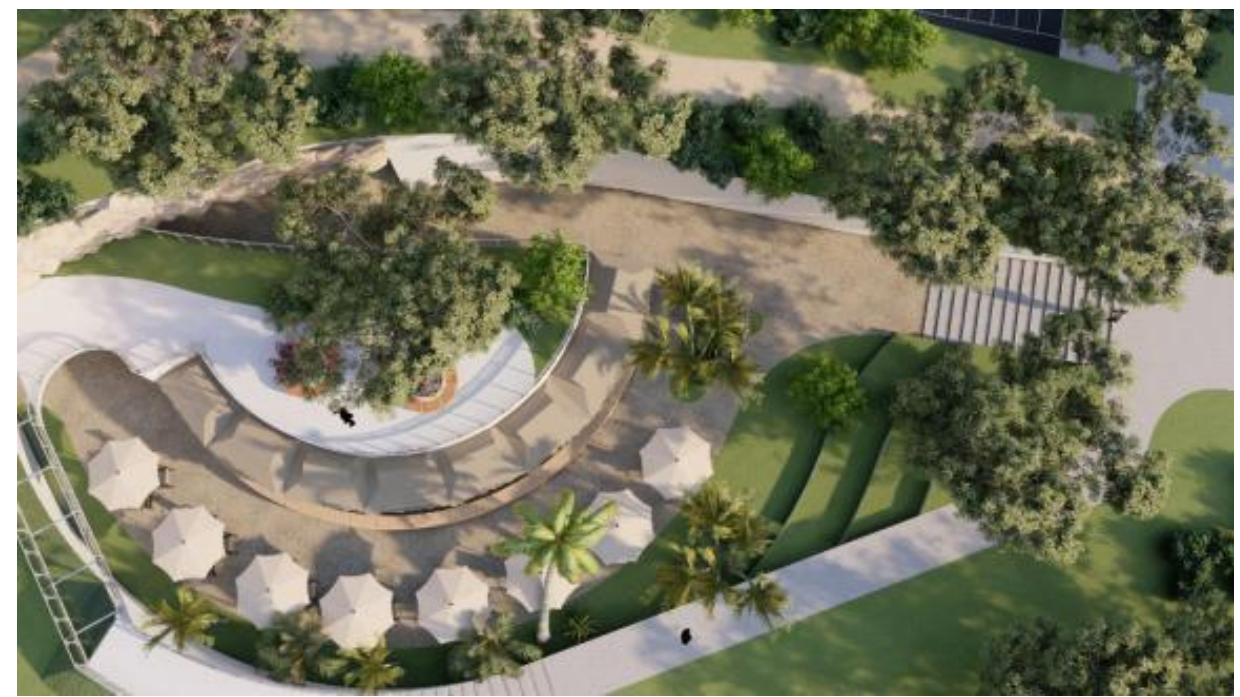

Gambar 6. Visualisasi Area Makan

Sumber : Penulis, 2020

\section{Area Jogging dan Taman}

Area penghijauan pada proyek ini bertujuan sebagai upaya penyediaan ruang terbuka yang sangat dibutuhkan masyarakat kawasan Kemayoran. Upaya menggabungkan arsitektur dengan alam ini juga bertujuan agar proyek ini juga dapat berfungsi sebagai taman kota yang memberikan fungsi sebagai ruang interaksi sosial dan juga sarana rekreasi. Penggunaan Landscape Architecture ini bertujuan agar masyarakat tidak merasakan berada didalam suatu bangunan dan juga menghindari menambah sebuah bangunan yang sudah berada di kawasan padat. Area jogging ini juga berbentuk ramp dan mengitari kawasan, selain sebagai penggiring pengunjung melihat setiap sisi bangunan namun juga berfungsi sebagai alat untuk merangsang hormon endorfin yang memiliki banyak kegunaan seperti mengurangii rasa stress dan juga meningkatkan mood yang akan sangat berguna bagi masyarakat sekitar.

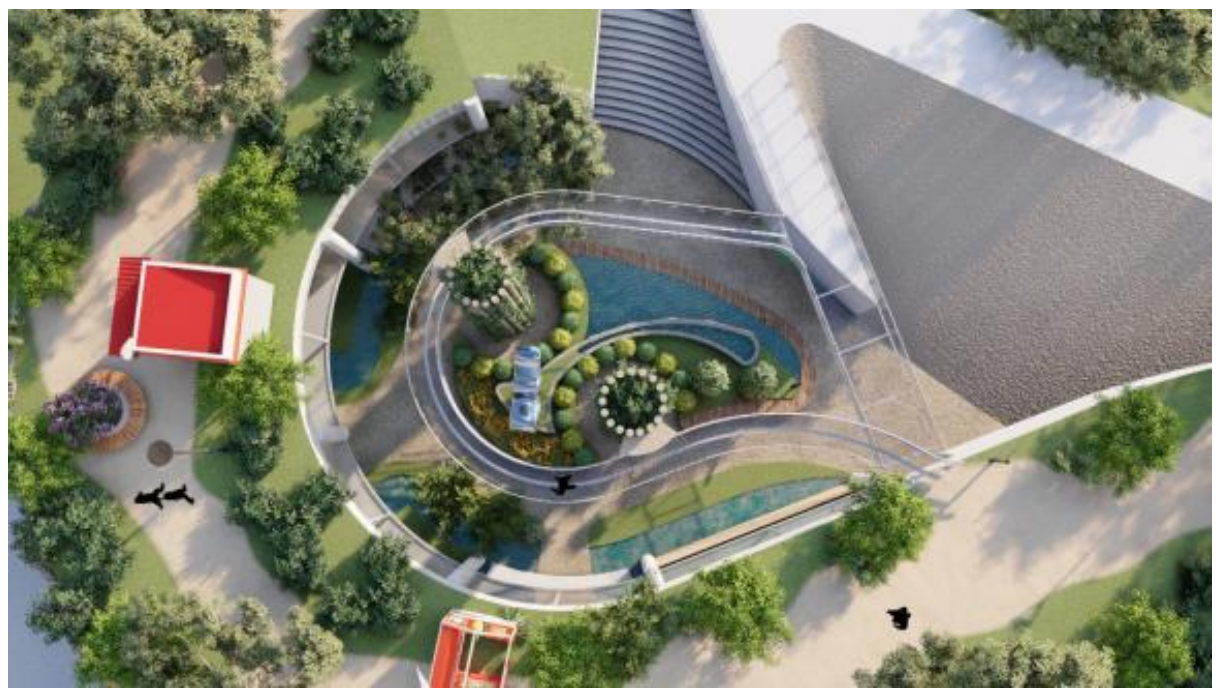

Gambar 7. Area Jogging Track

Sumber: Penulis, 2020

\section{Konsep Bangunan}

Konsep massa bangunan berorientasi pada sirkulasi kawasan sekitar, pertama-tama massa pada lantai dasar dibentuk menyesuaikan sirkulasi kawasan sehingga first place dan second place tercapai pedestrian. Kemudian pemberian kontur tanah dan permainan peil pada lantai 
satu bertujuan merangsang hormone endorfin pengguna bangunan. Dilanjutkan dengan sirkulasi melingkar pada lantai dua sehingga pengguna dapat melihat seluruh sisi bangunan. Pembentukan massa diatasnya dengan bentuk melingkar dan berkontur ramp agar pengguna dapat menaiki bangunan tanpa disadarinya.

Pada perancangan denah bangunan, yang menjadi pokok pemikiran utama adalah sirkulasi dalam bangunan yang nantinya dapat mempengaruhi psikologi pengunjung serta bentuk sirkulasi yang dapat menggiring pengunjung mengitari kawasan. Pada lantai 1 dalam upaya membaurkan bangunan dengan landscape maka unsur-unsur bangunan seperti kolom dan dinding dicoba dikurangi dengan upaya seperti penggantian kolom pada lantai 1 dengan menggunakan perbedaan peil tanah sebagai penunjang bangunan serta penggunaan kolam dan air menggantikan dinding sebagai pembatas antar ruang.

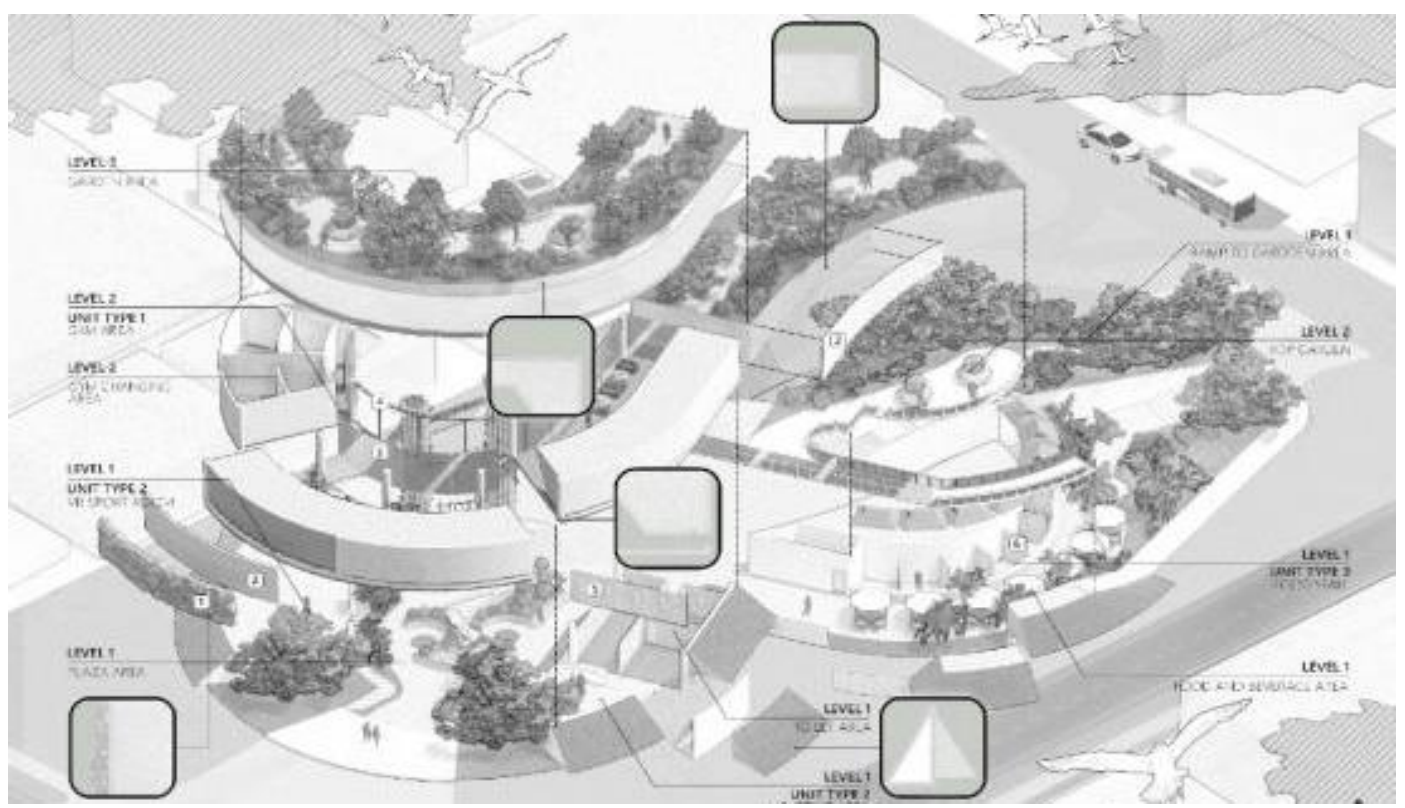

Gambar 8. Massa Bangunan

Sumber: Penulis, 2020

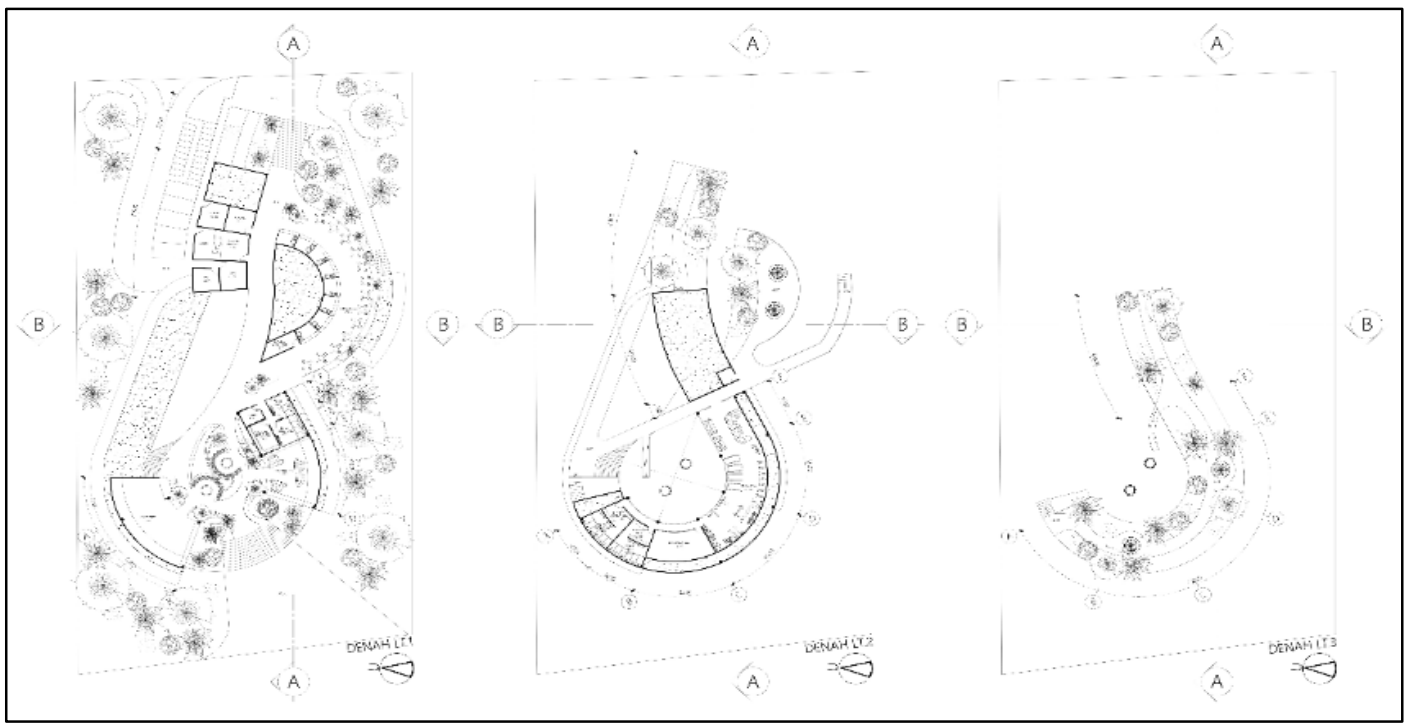

Gambar 9. Denah Bangunan

Sumber: Penulis, 2020 


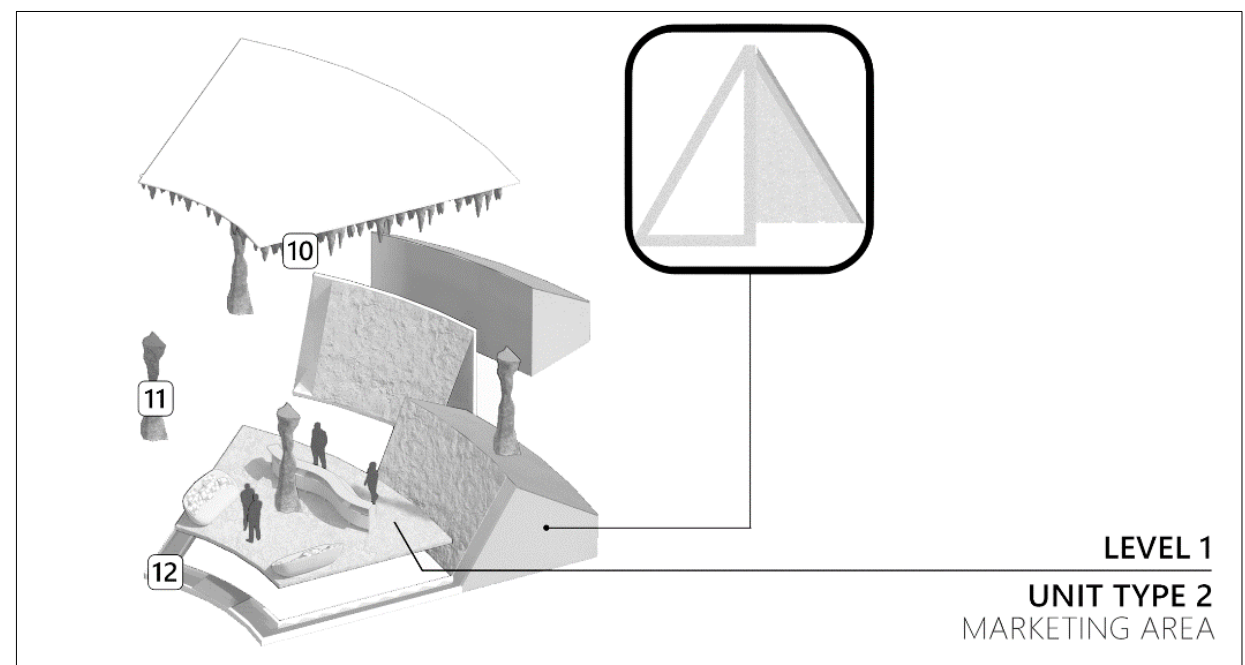

Gambar 10. Exploded Unit Type 1

Sumber: Penulis, 2020

Unit pada lantai satu juga didesain dengan cara menutupi keberadaan unsur bangunan. Perbedaan peil tanah pada lantai 1 juga digunakan pada unit ini sebagai pembatas ruang serta unsur-unsur bangunan lain seperti kolom dan plafon juga dibentuk sedemikian rupa untuk memimic bentuk alam seperti contohnya plafon pada unit dibentuk menyerupai bentuk stalactites dan juga kolom dalam unit ruang marketing dibentuk menyerupai bentuk stalacmites. Penggunaan material bebatuan pada lantai juga digunakan untuk melengkapi upaya menyembunyikan keberadaan unsur bangunan.

Pada lantai dua terdapat area gym yang berletakan langsung dibawah area taman. Maka dari itu pembentukan planter box yang berada diplafon area gym dibuat dengan bentuk yang berbeda agar tidak mengganggu aktivitas olah raga dibawahnya serta memaksimalkan luasan ruang area gym. Serta plafon area gym juga dibentuk dari rangkaian kayu yang disusun tidak rata serta bergelombang bertujuan agar dapat meningkatkan unsur organik yang nantinya juga ditutupi dengan tanaman rambat sehingga landscape yang berada didalam kawasan tidak hanya berpusat diluar bangunan namun juga mempengaruhi dalam ruangan.

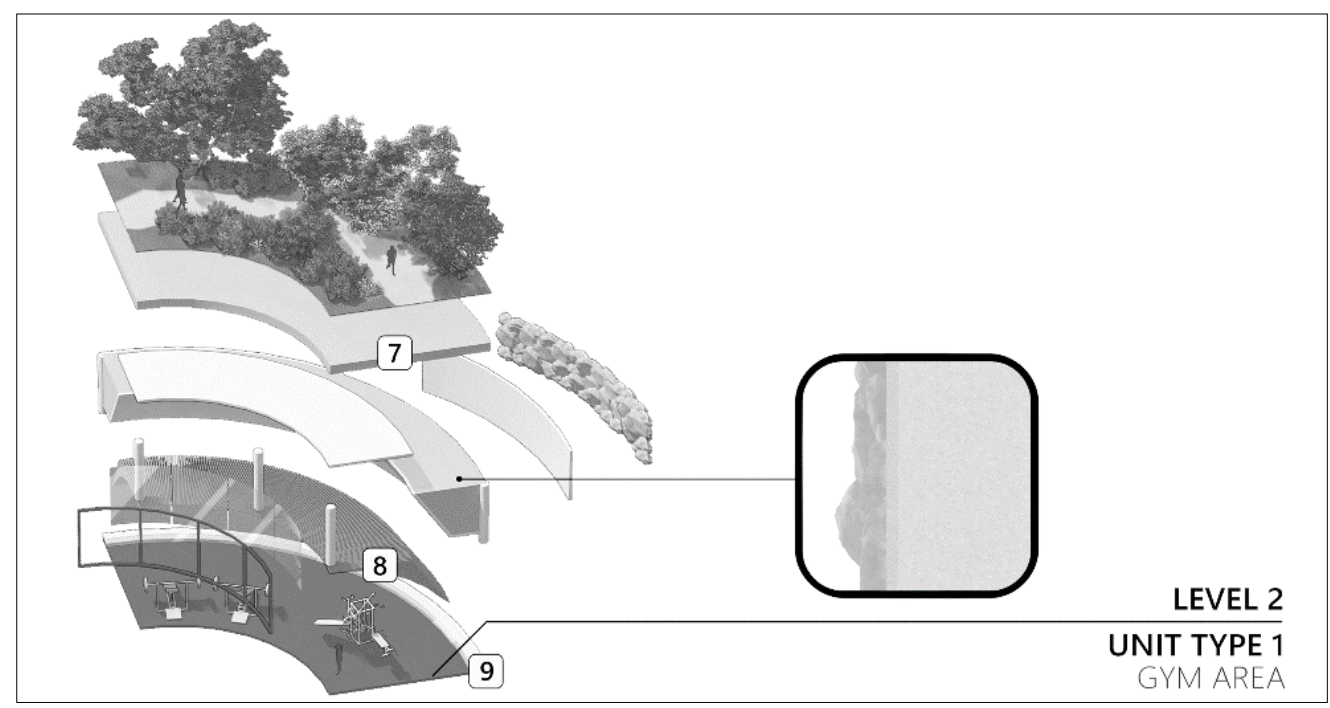

Gambar 11. Exploded Unit Type 2

Sumber: Penulis, 2020 


\section{KESIMPULAN DAN SARAN \\ Kesimpulan}

Berdasarkan hasil analisis dan data didapatkan kesimpulan yang menjadi landasan dan gagasan utama dalam perancangan proyek Fasilitas Olah Raga Hijau Kemayoran. Secara garis besar, Third Place adalah sebuah tempat yang membuat pengguna merasakan rasa nyaman berada dalam proyek. Maka dari itu desain dari Third Place harus dapat memenuhi kebutuhan masyarakat. Desain pada proyek didapatkan dari hasil pemikiran terhadap dampak perilaku masyarakat sekitar serta teori tentang efek arsitektur terhadap pengguna bangunan. Setiap liku dalam desain bangunan bertujuan untuk memicu interaksi dan psikologi pengunjung. Pemilihan bahan serta permainan tinggi peil lantai juga berpengaruh untuk mempengaruhi psikologi pengguna. Melalui Fasilitas Olah Raga Hijau Kemayoran bertujuan membantu kehidupan sosial masyarakat yang tinggal di kawasan Kemayoran yang memiliki kecenderungan hidup menyendiri untuk lebih mudah bersosialisasi serta membantu memberikan ruang terbuka hijau bagi masyarakat sekitar yang tinggal di kawasan kota yang padat.

\section{Saran}

Tingkat kepadatan kota yang terus meningkat membuat masyarakat semakin mudah untuk stress, hal ini membuat kebutuhan ruang untuk mengurangi tingkat stress suatu kawasan semakin dibutuhkan. Third Place atau ruang ketiga merupakan upaya dalam memberikan ruang interaksi dan bersantai dalam kawasan yang juga berguna sebagai tempak relaksasi dan pergi sejenak dari kehidupan perkotaan yang padat.

\section{REFERENSI}

Andrahan, O. (2012). Fungsi Taman Kota Metro Sebagai Ruang Terbuka Publik.

Bungas, M. (2017). Revitalisasi dan Urban Renewal Kawasan Kemayoran Blok A.

Christina, C. (2015). Analisa Dampak Kepadatan Penduduk Terhadap Kualitas Hidup Masyarakat Provinsi Jawa Tengah.

Coburn, A. (2019). Psychological Responses to Natural Patterns in Architecture.

Collins, D. N. (2020). Effect of Early Sport Participation on Self-esteem. The Sport Journal.

Davis, A. (2015). Social Bonds and Excercise: Evidence for a Reciprocal. Plos One.

Evans, G. W. (1984). Environmental Stress. Irvine: Cambridge University Press.

Hari H. S., H. E. (2015). Tingkat Kenyaman Taman Kota sebagai Ruang Interaksi Masyarakat Perkotaan.

Harvina, E. A. (2016, Oktober 25). Sulitnya Melakukan Interaksi Terhadap Masyarakat Kota. Retrieved from Kompasiana:

https://www.kompasiana.com/ersa17/580f69750523bdf02863672c/sulitnya-melakukaninteraksi-sosial-pada-masyarakat-kota

How Does Exercise Help with Social Skills ? (2016, September 14). Retrieved from Tiger Tennis Academy: https://www.tigertennisacademy.com/how-does-exercise-help-with-socialskills/

Jamaludin, M, A.N. (2017). SOSIOLOGI PERKOTAAN Memahami Masyarakat Kota dan Problematikanya. Bandung: CV Pustaka Setia.

Janetius, S. (2016). Art, Culture and Gender: The Indian Psyche. Mishil \& Js Publishers.

Jaya, M. A. (2018). Transformasi Tempat Ketiga (third place) dari Ruang Dalam (indoor) Menuju Ruang Luar (outdoor): Studi Kasus kota Palembang.

Kusmaryani, R. E. (2015). Fungsi Psikologis Taman Kota.

Muhlisin, D. A. (2019, Februari 22). Hormon Endorfin: Fungsi, Efek Kelebihan Dan Kekurangan \& Efek Samping. Retrieved from Honestdocs: https://www.honestdocs.id/hormonendorfin 
Nauert, R. P. (2019, Juni 15). Physical Activity Helps Improve Social Skills. Retrieved from PsychCentral: https://psychcentral.com/news/2018/03/15/physical-activity-helpsimprove-social-skills/12120.html

Oldenburd, R. (1989). The Great Good Place. Da Capo Press.

Opie, R. (2017). Dietary Recommendation for the Prevention of Depression, Nutritional neuroscience, 161-171.

Ruchimat, D. L. (2007). Proyek Pembangunan Rukan \& Apartemen Palazzo.

Uma Naidoo, M. (2018). Gut Feeling: How food affect your mood. 
